\title{
Myeloid Neoplasms with Germline RUNX1 Mutation
}

National Cancer Institute

\section{Source}

National Cancer Institute. Myeloid Neoplasms with Germline RUNX1 Mutation. NCI

Thesaurus. Code C151903.

An autosomal dominant syndrome characterized by abnormalities in platelet number and function and enhanced risk of developing myelodysplastic syndrome/acute myeloid leukemia at a young age. Patients have germline monoallelic mutations in RUNX1 gene. The clinical presentation is variable, even within the same family. Most affected individuals have a mild to moderate bleeding tendency. Platelet counts are normal or mildly reduced, with normal platelet morphology and variable degrees of platelet dysfunction. Distinct families with germline RUNX1 mutations exhibit varying risks of development of myeloid neoplasms with 11-100\% (median: 44\%) of family members affected. (WHO 2017) 